\title{
Historical Vignettes - Anaesthesia in Sri Lanka in the 1950s
}

\author{
B Wickramasinghe* \\ Retired Consultant Anaesthetist, \\ Founder Member, College of Anaesthesiologists of Sri Lanka.
}

When the Second World War broke out the army ordered us out and occupied our village of Koggala. I had just passed the London Matriculation examination. My school education got disrupted for nearly five years as we had to move to a village in the interior of the Galle district. This delayed my entry to Medical College. I passed out of Medical College in 1955 at the age of 34 years. At that time there was no internship and my first appointment was to Batticaloa Hospital. There were 3 house officers. One for medical wards, one for surgical wards and the third one for obstetrics. In addition, the three house officers took turns to work in the out patient department. I was looking after the medical wards with the DMO as the acting physician but he never came to the wards. The surgeon was a senior MBBS officer who had gained a lot of experience in surgical work under a consultant surgeon. The obstetrician and gynaecologist was an experienced officer with the Diploma in Obstetrics \& Gynaecology. Since all three House Officers were new, a senior House Officer who was already in Batticaloa had his transfer delayed by a few weeks so he could train us.

During operating sessions, the ward House Officer assists the surgeon and one of the other House Officers had to be the anaesthetist. I had had no training in anaesthesia at all. My first experience as an anaesthetist was when I found a trolley with a bottle of chloroform and a U-shaped mask with perforations on top filled with gauze. With a measuring cylinder, a dram of chloroform was measured and this was poured into the mask until the gauze got soaked with the chloroform. Vaseline was applied to the edge of the mask to prevent irritation of the skin. The mask was then held over the nose and mouth of the patient. The eye signs were observed. First the eye lash reflex is lost. The pupils start dilating and then gradually constrict. When the pupils are pin point, the surgeon was asked to start operating. By observing the eye signs more chloroform was poured into the mask to keep the patient under anaesthesia till the end of the operation. For post operative pain either pethidine or morphine was administered.

Most of the cases were done under spinal analgesia. Lumbar puncture was done between either L2/3 or L 3/4 interspace with the patient seated on the operation table. Usually for a laparotomy 7 to $8 \mathrm{ml}$ of light nupercaine was injected. For haemorrhoids, $1.5 \mathrm{ml}$ of the heavy solution was injected.

My stay at Batticaloa was cut short by the communal troubles that erupted in 1956. I was sent on relief duty to Inginiyagala Hospital which at that time was staffed by American doctors. The operation theatre was better equipped than even the operation theatres at General Hospital, Colombo. After a short time at Inginiyagala, I was transferred as HO Anaesthesia Galle Hospital. I had no proper training in anaesthesia and learnt what to do from Dr Abeysiriwardene the House Officer who was in Galle. He has had two weeks training in Colombo. There was a Boyle's apparatus available at Galle. The volatile agents available were diethyl ether and trichloroethylene (trilene). One of the surgeons, Dr Abeysundera encouraged me to continue in anaesthesia while the others found fault with the Department of Health for sending an untrained person as anaesthetist. The surgeon at Galle got a heart attack and relief surgeons were sent to Galle. One of them Dr HD Gunatilleke who had come from Kalutara asked me to apply for post of relief $\mathrm{HO}$ Anaesthesia at Kalutara.

I also remember that when I came to Galle from Batticaloa there was an "Iron Lung" fixed in a room close to the operation theatre at Galle. It had not been used and we were 
not bothered about it. However, one day towards the end of the year, we were informed that a man who had attempted suicide by hanging was to be brought to the hospital. A few of the medical officers rushed into the room where the Iron Lung was and examined the machine. No one knew how to operate the machine, so we tried moving various knobs and handles and found the way to operate it. We put the patient into the machine and started it. It started functioning with a frightening noise. It was working perfectly and we observed the chest movements which were perfect. Sadly, there was no improvement in the patient's condition which was not surprising as a number of hours had elapsed before he was brought to the hospital.

In 1964 I moved to Kalutara and I was made permanent HO Anaesthesia there. Kalutara hospital was better equipped than Galle hospital. Dr Gunatilleke used to perform major surgery like laryngopharyngectomy and oesophagectomy at Kalutara. He forced me to apply for postgraduate leave and arranged for me to meet the Postgraduate Dean in London.

Together with my wife and baby son I left for London by boat in 1965. I was given a training post at Queen Mary Hospital in East London. I was successful in the Diploma in Anaesthesia examination and returned to Sri Lanka in 1966.

Dr Gunatilleke had by then been transferred to Galle and he encouraged me to come to Galle. At that time there were some internal problems at Galle between the surgeons and anaesthetist and theatre work had come to a virtual standstill. When I reported to the Department on my return I was given a letter of appointment as the Consultant Anaesthetist, Galle Hospital. I reported for duty and was able to sort out the problems and ensure that surgery resumed. Dr Ranjen Fernando, a past president of the College was my first trainee in anaesthesia. The standard of anaesthesia in Galle gradually improved. Halothane was introduced around 1970. Monitoring was introduced in 1992. The Intensive Care Unit was started in 1995 but before this patients were ventilated in the wards.
I reached 60 years of age in 1981 and was due to retire but no one was prepared to come to Galle. The Director of Health Services appealed to the Minister of Health who prepared a cabinet paper and got approval for me to continue if I felt I was fit. I retired at the age of 73 years. By then Galle Hospital had become a Teaching Hospital and was a much changed place from where I started work in 1956. 